\title{
Risk Factors for Persistent Wheezing Beyond Six Years of Age: Cohort Study
}

\author{
Sudhir Sane ${ }^{1}\left[\mathbb{D} \cdot\right.$ Jayashree Balip ${ }^{1}$
}

Received: 13 August 2020 / Accepted: 23 November 2020 / Published online: 27 November 2020

(C) Dr. K C Chaudhuri Foundation 2020

To the Editor: Early childhood wheeze has variable prognosis. Some children stop wheezing by sixth birthday (transient wheeze) while others persist to wheeze (persistent wheeze) [1]. There are many population-based studies from developed countries analyzing risk factors for persistent wheeze. These risk factors commonly described are atopy, allergic rhinitis, history of wheezing, and positive family history $[2,3]$. The risk factors may be different in developing countries.

We are presenting here is a clinic-based study, done on cohort of children registered in asthma clinic to find out the risk factors associated with persistent wheeze. Children with recurrent, prolonged or severe respiratory symptoms were registered in asthma clinic. We obtained institutional ethical clearance and consent from the caretakers. The participants recruited had to satisfy following criteria: registered in asthma clinic as preschoolers, presently more than 6-y-old and visited outpatient for routine care during study period. The minimum follow-up period needed was one year.

Current demographic data and status of wheezing in past one year was entered. The data about their risk factor profile was retrieved from asthma clinic records. Out of 677 eligible children, 200 visited us during the study period and hence included. Demographic and risk factor profile of these 200 children did not differ statistically from remaining 477 . Mean period of follow-up was 55.715 months (Range 12102 months). The characteristics at the time of entry to asthma clinic were: mean age 41.99 mo, recurrent wheeze $65 \%$, allergic rhinitis $37.5 \%$, atopic dermatitis $33 \%$ and positive family history $76 \%$. Wheezing was recorded beyond sixth birthday in $45 \%$ children.

Sudhir Sane

sudhirs4@hotmail.com

1 Department of Pediatrics, Jupiter Lifeline Hospitals, Off Eastern Express Highway, Thane West, Maharashtra 400602, India
Recurrent wheeze in preschoolers (physician recorded $>$ three times in previous year) was significantly associated with persistent wheeze (OR 9.3,95\% CI 4.1-21). This is reported before $[2,3]$. There was no association between persistent wheeze and atopic dermatitis, allergic rhinitis or family history unlike the studies quoted above.

This may suggest different risk-factor profile associated with persistent wheeze in developing countries [4].

Limitations of our study are absence of lung-function data and possibly nonrandomized recruitment.

Ethical committee clearance obtained from Institutional ethics committee on 4th Feb 2020.

\section{Compliance with Ethical Standards}

Conflict of Interest None.

\section{References}

1. Brand PL, Caudri D, Eber E, et al. Classification and pharmacological treatment of preschool wheezing: changes since 2008. Eur Res J [Internet]. 2014;43(4):1172-7.

2. Martinez FD, Wright AL, Taussig LM, Holdberg M, Morgan WJ. Asthma and wheezing in the first six years of life. N Engl J Med. 1995;332:133-8.

3. Henderson J, Granell R, Heron J, et al. Associations of wheezing phenotypes in the first 6 years of life with atopy, lung function and airway responsiveness in mid-childhood. Thorax. 2008;63:974-80.

4. Bush A. Diagnosis and management of asthma in children. BMJ. 2015;350:h996.

Publisher's Note Springer Nature remains neutral with regard to jurisdictional claims in published maps and institutional affiliations. 